\title{
Sub-lethal levels of carvacrol reduce Salmonella Typhimurium motility and invasion of porcine epithelial cells
}

\author{
Jeanine Inamuco ${ }^{\mathrm{a}}$, Andreas K.J. Veenendaal ${ }^{\mathrm{b}}$, Sara A. Burt ${ }^{\mathrm{c}}$, Jan A. Post ${ }^{\mathrm{d}}$, \\ Johanna L.M. Tjeerdsma-van Bokhoven ${ }^{\mathrm{a}}$, Henk P. Haagsman ${ }^{\mathrm{a}}$, Edwin J.A. Veldhuizen ${ }^{\mathrm{a}, *}$ \\ ${ }^{a}$ Department of Infectious Diseases and Immunology, Division Molecular Host Defence, Faculty of Veterinary Medicine, Utrecht University, The Netherlands \\ ${ }^{\mathrm{b}}$ Department of Infectious Diseases and Immunology, Division Infection Biology, Faculty of Veterinary Medicine, Utrecht University, The Netherlands \\ ${ }^{\mathrm{c}}$ Institute for Risk Assessment Sciences, Division Veterinary Public Health, Faculty of Veterinary Medicine, Utrecht University, The Netherlands \\ ${ }^{\mathrm{d}}$ Biomolecular Imaging, Department of Biology, Faculty of Science, Utrecht University, The Netherlands
}

\section{A R T I C L E I N F O}

Article history:

Received 26 January 2011

Received in revised form 14 December 2011

Accepted 19 December 2011

\section{Keywords:}

Salmonella

Carvacrol

Epithelial cells

Porcine

Antibiotic

Defensin

\begin{abstract}
A B S T R A C T
The European ban on the use of antibiotic growth promotors has increased the search for new alternatives to prevent pig intestinal microbial diseases and to stimulate growth. The addition of essential oils or components thereof, such as carvacrol, to pig feed is a promising alternative. In this report we determined the effect of sub-lethal concentrations of carvacrol on Salmonella Typhimurium. At concentrations where growth of Salmonella was not inhibited, carvacrol completely inhibited motility of the bacterium. This loss of motility was not due to the loss of the flagellum or to ATP shortage upon carvacrol treatment. Adhesion of Salmonella to IPEC-J2, porcine intestinal epithelial cells, was not affected by carvacrol but invasion was significantly reduced. In addition, the epithelial gene expression of porcine $\beta$-defensin 2 , an innate immune response to Salmonella infection, was reduced when Salmonella was exposed to carvacrol. This indicates that invasion but not adhesion of Salmonella triggers the porcine $\beta$-defensin 2 expression of porcine epithelial cells.
\end{abstract}

(c) 2012 Elsevier B.V. All rights reserved.

\section{Introduction}

The European ban on the use of antibiotic growth promotors has increased the search for new alternatives to prevent pig intestinal microbial diseases and to stimulate growth. The addition of essential oils or components thereof, such as carvacrol, to pig feed is a promising alternative. Carvacrol is one of the main components of oregano oil, and has antibacterial but also antifungal and insecticidal activity against a wide range of microorganisms (Burt, 2004; Chami et al., 2005; Panella et al., 2005; Tampieri et al., 2005). The exact mode of action of carvacrol

\footnotetext{
* Corresponding author at: Department of Infectious Diseases and Immunology, Division Molecular Host Defence, Faculty of Veterinary Medicine, Utrecht University, P.O. Box 80.165, 3508 TD, Utrecht, The Netherlands. Tel.: +31 30 2535361; fax: +31302532333.

E-mail address: E.J.A.Veldhuizen@uu.nl (Edwin J.A. Veldhuizen).
}

is not known yet, but most studies point towards membrane disruption as the main mechanism.

If carvacrol is to be applied as an additive in animal feed, minimal inhibitory concentration (MIC) or minimal bactericidal concentration (MBC) levels are not likely to be reached in the gastrointestinal tract where it should exert its function. Not only will carvacrol be diluted while traveling through the intestinal tract, in vitro studies have also shown that it can bind to protein and lipid components of feed, lowering the effective concentration of carvacrol available for activity against microorganisms (Si et al., 2006; Veldhuizen et al., 2007). In this report we describe the effect of sub-lethal concentrations of carvacrol on Salmonella enterica serovar Typhimurium ( $S$. Typhimurium). At concentrations where growth of $S$. Typhimurium was not inhibited the effect of carvacrol on motility and on adhesion and invasion characteristics of this bacterium were determined. In addition, the cytotoxic 
effect of carvacrol on intestinal epithelial cells and indirect effects on the host response towards Salmonella invasion were investigated.

\section{Materials and methods}

\subsection{Bacterial strains and culture conditions}

Four S. Typhimurium strains and one S. enterica serovar Enteritidis (S. Enteritidis) strain were used: $S$. Typhimurium phage type $510, S$. Typhimurium phage type 656 (both clinical isolates from pig intestine), S. Typhimurium DT104 (Hendriksen et al., 2004), S. Typhimurium ATCC 14028, and S. enterica serovar Enteritidis 90-13-706 (Van Asten et al., $2000)$. Overnight $(\mathrm{o} / \mathrm{n})$ cultures of Salmonella strains were prepared freshly for every experiment by cultivation from frozen stock at $37^{\circ} \mathrm{C}$ for $16 \mathrm{~h}$ in Trypton Soy Broth (TSB, Oxoid Basingstoke, United Kingdom). Before use in the antimicrobial assays described below, the optical density of the suspension was measured using a Pharmacia Ultrospec III spectrophotometer (Pharmacia Biotech, Roosendaal, the Netherlands) at $620 \mathrm{~nm}$, and the suspensions were diluted in TSB to the appropriate bacterial density needed in the experiments.

\subsection{Cell culture}

The IPEC-J2 cell line (Schierack et al., 2006) was maintained in 50\% Dulbecco's Modified Eagle Medium and 50\% Nutrient Mixture F12 (Ham) (1:1 DMEM/F12) (GIBCO, Invitrogen, Carlsbad, CA), supplemented with $10 \mathrm{U} /$ $\mathrm{ml}$ penicillin, $10 \mathrm{mg} / \mathrm{ml}$ streptomycin, $2 \mathrm{mM}$ L-glutamine and $5 \%(\mathrm{v} / \mathrm{v})$ fetal bovine serum (all provided by GIBCO, Invitrogen, Carlsbad, CA). Cells were grown in monolayers at $37{ }^{\circ} \mathrm{C}$ in $5 \% \mathrm{CO}_{2}$ atmosphere. Medium was changed every other day and cells were passaged once a week. For infection experiments, cells were cultured in 12-well cell culture plates (Costar, Corning Incorporated, Corning, NY) and grown to confluent monolayers in 7 days. In all experiments IPEC-J2 cells were used between passages 80 and 100 . Human-derived enterocyte-like Caco-2 cells were cultured in Dulbecco's Modified Eagle Medium supplemented with $0.03 \%$ L-glutamine (Invitrogen life technologies, Carlsbad, CA), $1 \%$ non-essential amino acids, $10 \mathrm{mM}$ sodium bicarbonate, $25 \mathrm{mM}$ HEPES, $10 \mathrm{U} / \mathrm{ml}$ penicillin, $10 \mathrm{mg} / \mathrm{ml}$ streptomycin, and $20 \%$ fetal bovine serum in monolayers at $37^{\circ} \mathrm{C}$ in a $5 \% \mathrm{CO}_{2}$ atmosphere.

\subsection{Growth curves}

Growth curves of bacteria in TSB containing carvacrol were determined using a Bioscreen $C$ optical density (OD) reader (Oy Growth Curves AB Ltd., Helsinki, Finland) using software version 2.28. A stock preparation of $1 \mathrm{M}$ carvacrol was prepared in $96 \%$ ethanol and diluted in TSB to the appropriate concentration. Final ethanol concentrations never exceeded $2 \%(\mathrm{v} / \mathrm{v})$, to avoid an antibacterial effect of ethanol itself. From the $1 \mathrm{M}$ stock in ethanol a $5 \mathrm{mM}$ working solution was prepared in TSB, which was shaken vigorously for $2 \mathrm{~h}$ at $37^{\circ} \mathrm{C}$ to completely dissolve carvacrol in the growth medium. In a typical experiment, aliquots of
$100 \mu \mathrm{l}$ of Salmonella suspension containing $2 \times 10^{6}$ colony forming units (CFU)/ml were added to $100 \mu \mathrm{l}$ carvacrol in TSB. All wells were incubated for $18 \mathrm{~h}$ at $37^{\circ} \mathrm{C}$ with continuous shaking. Optical density (OD) measurements (broad filter $420-580 \mathrm{~nm}$ ) were obtained automatically every $30 \mathrm{~min}$. Each experiment was carried out three times with at least three replicates each time. Ten samples containing carvacrol concentrations between 0 and $2.5 \mathrm{mM}$ and a negative control containing no bacteria were tested in each experiment. The MIC value was defined as the lowest concentration where no increase in optical density was observed after $18 \mathrm{~h}$.

\subsection{Motility assay}

To assess the effect of carvacrol on bacterial migration, a colony grown $\mathrm{o} / \mathrm{n}$ on TSA was stabbed into semi-solid medium (1\% Bacto tryptone (Difco laboratories, Detroit), 0.5\% (w/v) NaCl, 0.35\% Agar (Difco laboratories, Detroit)) with or without carvacrol at final concentrations ranging from 0.0 to $1.0 \mathrm{mM}$. Bacterial swarming was assessed after incubation at $37^{\circ} \mathrm{C}$ for $24 \mathrm{~h}$. Motility of Salmonella was also qualitatively determined by the hanging-drop technique (Burt et al., 2007). For this, a droplet of the culture was suspended from a glass coverslip over a microscope slide with a central concavity and observed under a light microscope. The bacterial cells were observed at a magnification of 1000 .

\subsection{Detection of flagellin in carvacrol treated S. Typhimurium DT104}

S. Typhimurium DT104 cultures were grown to log phase in the presence of 0-0.8 mM carvacrol. After growth, cultures were normalized for optical cell density. One hundred microliter of cells were centrifuged $(10 \mathrm{~min}$, $16,000 \times g$ ), washed twice with PBS and separated on a $12 \%$ SDS PAGE gel and blotted onto nitrocellulose. Flagellin was detected on the western blot using anti-flagellin antibodies as described before (Burt et al., 2007).

\subsection{Electron microscopy}

S. Typhimurium DT104 cultures were grown to log phase in the presence of $0,0.5$ or $0.8 \mathrm{mM}$ carvacrol. Carbon coated copper grids with a Formvar support film were glow discharged just before the bacterial samples were placed on the grids. Bacteria attached to the grids during a $3 \mathrm{~min}$ incubation, which was followed by a rinsing step of $10 \mathrm{~s}$ upside down on a $30 \mu \mathrm{l}$ droplet of water. Subsequently, negative staining was achieved by an incubation of $3 \mathrm{~min}$ on $2 \%$ uranyl acetate in water and removal of the excess with filter paper. Samples were examined in a FEI Tecnai 12 microscope at an accelerating voltage of $100 \mathrm{kV}$.

\subsection{ATP leakage assay}

To determine whether sub-MIC concentrations of carvacrol induce release of ATP, both intra and extracellular ATP levels were measured. Carvacrol (0.5 or $0.8 \mathrm{mM})$ or the equivalent amount of ethanol $(0 \mathrm{mM}$ 
carvacrol control) was added at the start of Salmonella growth in TSB medium. Cultures were grown at $37^{\circ} \mathrm{C}$ with agitation for $3 \mathrm{~h}$ or $18 \mathrm{~h}$. After growth, cultures were normalized for optical cell density and $1 \mathrm{ml}$ centrifuged $\left(10,000 \times \mathrm{g}, \quad 10 \mathrm{~min}, 4^{\circ} \mathrm{C}\right)$. Culture supernatants were centrifuged $\left(15,000 \times \mathrm{g}, 15 \mathrm{~min}, 4^{\circ} \mathrm{C}\right)$ to remove remaining cells and cell debris and then kept on ice. Cell pellets were resuspended in lysis buffer ( $100 \mathrm{mM}$ Tris, $4 \mathrm{mM}$ EDTA, $\mathrm{pH}$ 7.75 ) to an $\mathrm{OD}_{600 \mathrm{~nm}}=2$. To $100 \mu$ l of suspension, $900 \mu \mathrm{l}$ of boiling lysis buffer was added. Samples were incubated for $2 \mathrm{~min}$ at $100^{\circ} \mathrm{C}$, placed on ice and centrifuged $(1000 \times \mathrm{g}$, $1 \mathrm{~min}, 4^{\circ} \mathrm{C}$ ). One hundred microliters of cell lysates and culture supernatants were mixed with an equal amount of luciferase reagent from the ATP Bioluminescence Assay CLS II kit (Roche Diagnostics, Mannheim, Germany) and luciferase activity was measured using a luminometer (TD20/20, Turner Designs, Sunnyvale, CA, USA). The ATP concentration was calculated from an ATP standard curve.

\subsection{Cytotoxicity of carvacrol}

Susceptibility of IPEC-J2 cells to cytotoxic effects of carvacrol was evaluated using the trypan blue exclusion assay. IPEC-J2 cells were grown to confluency in microtiter plates and subjected to $0-1.0 \mathrm{mM}$ carvacrol in plain DMEM/F12 (without serum, L-glutamine or antibiotics) for $2 \mathrm{~h}$. Subsequently, cells were washed 3 times with PBS and detached from the well bottom using Trypsin/EDTA (Invitrogen life technologies, Carlsbad, CA). After inhibition of trypsin activity by addition of full medium, IPEC-J2 cells were centrifuged and resuspended in plain DMEM/F12 medium, mixed $1: 1$ with $0.4 \%$ trypan blue and the percentage of non-viable (blue) cells were counted after $1 \mathrm{~min}$ but within $5 \mathrm{~min}$. Experiments $(n=5)$ were performed in triplicate on separate days and on average 300 cells were counted for each condition.

\subsection{Adhesion and invasion of porcine epithelial cells}

S. Typhimurium DT104 was grown to log phase in the presence of $0,0.5$ or $0.8 \mathrm{mM}$ carvacrol. Bacteria were centrifuged and resuspended in plain DMEM/F12 medium to a density of $1 \times 10^{8} \mathrm{CFU} / \mathrm{ml}$. IPEC-J2 cells were grown to confluency in 12-well tissue-culture plates, washed three times with plain medium, and incubated with $1 \mathrm{ml}$ of the bacterial solution for $1 \mathrm{~h}$ at $37^{\circ} \mathrm{C}$. The monolayers were washed three times with plain medium and lyzed in $1 \%$ Triton X-100 in PBS at room temperature for 5 min in order to release the bacteria. The suspensions were serially diluted and $100 \mu \mathrm{l}$ of each dilution was plated on Trypticase Soy Agar (TSA, Oxoid Limited). The plates were incubated for $24 \mathrm{~h}$ at $37^{\circ} \mathrm{C}$. Numbers of cell associated bacteria were calculated as total (adhering and intracellular) bacterial CFU. In the invasion assay, the IPECJ2 monolayers in the wells were washed once with $1 \mathrm{ml}$ warm plain medium after $1 \mathrm{~h}$ incubation with bacteria and then incubated for $2 \mathrm{~h}$ with $1 \mathrm{ml}$ of $300 \mu \mathrm{g} / \mathrm{ml}$ colistin in warm plain DMEM/F12 to kill extracellular bacteria. Cells were washed three times with plain DMEM/F12, and finally lyzed in $1 \%$ Triton X-100. The number of intracellular bacteria was determined by colony-plating as described above. Similar experiments were performed with Caco-2 cells.

\subsection{Effect of carvacrol treatment of Salmonella on porcine $\beta$ defensin-2 gene expression of IPEC J2 cells}

S. Typhimurium DT104 was grown to log phase in the presence of $0,0.5$ and $0.8 \mathrm{mM}$ carvacrol. Cells were centrifuged and resuspended in plain DMEM/F12 medium to a density of $1 \times 10^{8} \mathrm{CFU} / \mathrm{ml}$ and added to a confluent monolayer of IPEC-J2 cells in a 12-wells plate. After $3 \mathrm{~h}$ of incubation, cells were washed twice and incubated with full medium containing $300 \mu \mathrm{g} / \mathrm{ml}$ colistin. After 6 and $24 \mathrm{~h}$, IPEC-J2 cells were dissolved in $1 \mathrm{ml}$ TRIzol (Invitrogen Life Technologies, Carlsbad, CA). Total cellular RNA was isolated according to the supplier's recommendation. Purity and quality of the RNA extracts was checked on $1 \%$ agarose gels and using UV absorption at 260/280 nm. Approximately 500 ng RNA was used to produce cDNA, using iScript (Bio-rad Laboratories BV, Veenendaal, The Netherlands) according to the manufacturer's recommendations. Quantitative determination of gene expression of porcine $\beta$-defensin 2 (pBD-2) was performed as described before (Veldhuizen et al., 2009).

\subsection{Detection of cytokine expression}

The effect of carvacrol treatment on the ability of S. Typhimurium to modulate cytokine production in IPEC-J2 cells was measured by means of enzyme-linked immunosorbent assay (ELISA). The expression levels of porcine TNF$\alpha$, IL-1 $\beta$, IL- 6 , and IL- 8 were measured using the commercially available DuoSet ELISA kits (R\&D Systems). IPEC-J2 cells were grown and infected as described in Section 2.10, subsequently after $3 \mathrm{~h}$ of incubation cells were washed twice and incubated with full medium containing $300 \mu \mathrm{g} /$ $\mathrm{ml}$ colistin. After 4, 6 and $24 \mathrm{~h}$, culture supernatants were collected and used for cytokine detection following the protocols provided by the manufacturer. All samples were centrifuged briefly at 500 for $3 \mathrm{~min}$ at room temperature to remove cell debris prior to use. The microtiter plates were read at an absorbance of $450 \mathrm{~nm}$.

\subsection{Statistical analyses}

Statistical analysis of variance was performed using SPSS Version 16.0 for Windows. All data were analyzed by the post hoc Bonferroni test. Significant differences between means were defined as $p<0.05$.

\section{Results}

\subsection{Growth curves}

The effect of carvacrol on the growth of $S$. Typhimurium DT104 is shown in Fig. 1. Up to $1 \mathrm{mM}$, carvacrol did not affect the growth rate of S. Typhimurium DT104 while at concentrations higher than $1 \mathrm{mM}$, a significant reduction in growth rate was observed. The minimal inhibitory concentration was $2 \mathrm{mM}$ while the MBC (as determined by plating out those wells without observable growth) was 


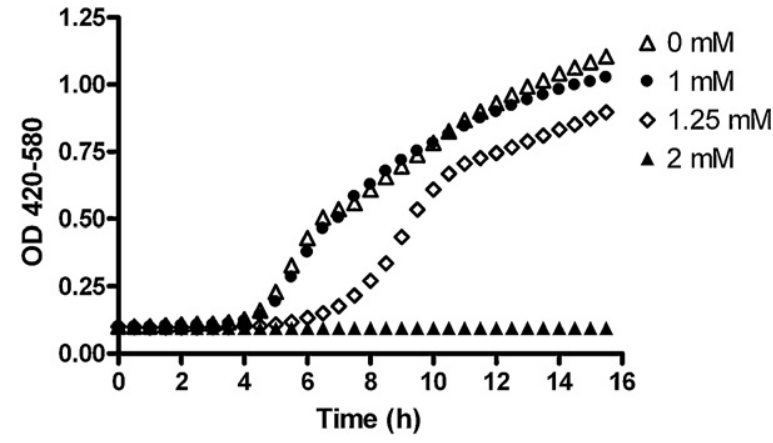

Fig. 1. Representative growth curves of $S$. Typhimurium DT104 in TSB in the presence of different concentrations of carvacrol. For clarity, only a selection of the tested carvacrol samples is depicted. Shown is the mean of quadruplicate samples in one experiment.

similar to the MIC. Similar results were obtained for the other four Salmonella strains, with only $S$. Enteritidis having a slightly lower MIC and MBC (1.75 mM, data not shown) indicating that the effect of carvacrol on growth is not Salmonella-strain specific.

\subsection{Motility}

Using soft agar plates, motility of all five Salmonella strains was determined in the presence of carvacrol. As depicted in Fig. 2 for S. Typhimurium DT104, motility was slightly reduced at $0.4 \mathrm{mM}$ and completely abolished at $1 \mathrm{mM}$ carvacrol. The four other strains showed similar reduced motility at these carvacrol concentrations (data not shown). These results show that motility is affected at lower concentrations than growth. Non-quantitative determination of motility using a light microscope showed complete loss of motility in solution at concentrations $>0.6 \mathrm{mM}$, for all Salmonella strains confirming the soft agar results (data not shown).

\subsection{Flagella presence and flagellin production}

The effect of carvacrol on the production of flagellin in $S$. Typhimurium DT104 was determined using electron

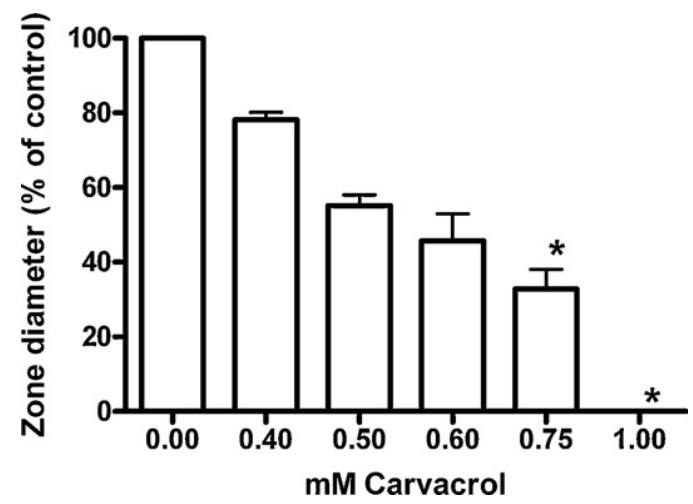

Fig. 2. Swarming of $S$. Typhimurium DT104 in soft agar plates. The relative zone diameter compared to the control ( $0 \mathrm{mM}$ carvacrol, set at $100 \%$ ) is presented as mean + SEM of three independent experiments. * indicates statistical significance. microscopy and western blot. Bacteria incubated with $0.5 \mathrm{mM}$ (not shown) or $0.8 \mathrm{mM}$ carvacrol possessed flagella as shown by negative staining of the Salmonella (Fig. 3). Using western blot, all samples showed an immunoreactive band at the expected size $( \pm 50 \mathrm{kDa})$ for flagellin with no observable difference in intensity (data not shown). This indicates that the reduced motility is not due to the loss of the flagellum of $S$. Typhimurium.

\subsection{ATP leakage}

In order to determine whether sub-lethal concentrations of carvacrol could result in energy depletion of the bacterium, ATP levels were measured after 3 and $18 \mathrm{~h}$ of growth in carvacrol containing medium. For log phase Salmonella (3 h growth) extracellular ATP levels were significantly higher for the $0.8 \mathrm{mM}$ carvacrol treated Salmonella indicating that ATP had indeed leaked out of the bacterium (Fig. 4A). Intracellular levels were not lowered showing that lost ATP was regenerated. For bacteria grown $\mathrm{o} / \mathrm{n}$ in the presence of carvacrol, intracellular levels were actually higher than the no-carvacrol control, while extracellular levels were slightly reduced

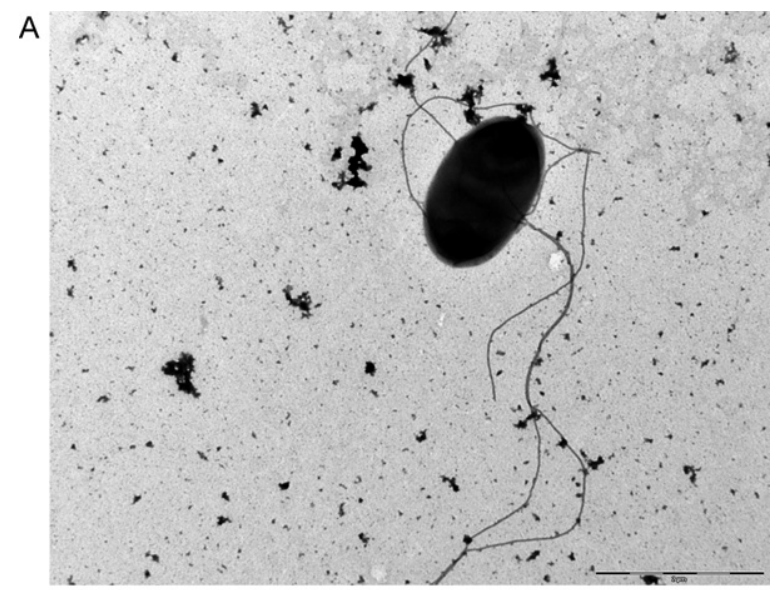

B

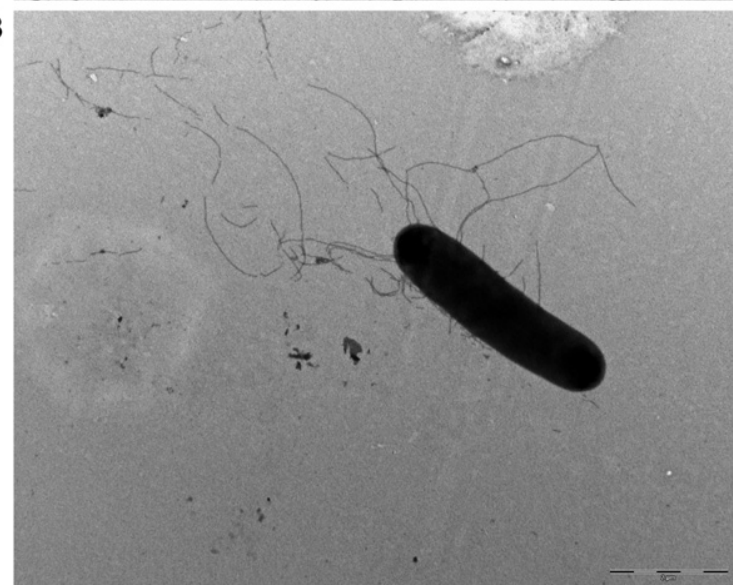

Fig. 3. Flagella are present on carvacrol-incubated $S$. Typhimurium. $S$. Typhimurium was grown for $3 \mathrm{~h}$ in the absence $(\mathrm{A})$ or presence $(\mathrm{B})$ of $0.8 \mathrm{mM}$ carvacrol. Bacteria were visualized using electron microscopy by negative staining. Scale bar represents $2 \mu \mathrm{m}$. 
(Fig. 4B). However, these differences were not statistically significant.

\subsection{Cytotoxicity of carvacrol}

The cytotoxic effect of carvacrol on IPEC-J2 intestinal cells is shown in Table 1. Although standard deviations were relatively high for this set of experiments, a clear increase in the number of dead cells with higher carvacrol concentrations was observed. At $1 \mathrm{mM}$ carvacrol, the highest concentration tested, $48 \%$ of IPEC cells were dead indicating that under these culture conditions carvacrol is toxic to this porcine epithelial cell line.

\subsection{Adhesion and invasion of intestinal cells}

Since motility of Salmonella is correlated to invasion, the adhesion and invasion characteristics of carvacrol treated bacteria were determined. The growth to log phase of $S$. Typhimurium DT104 in the presence of $0.5 \mathrm{mM}$ carvacrol resulted in a significant reduction in invasion (34\% of control) of IPEC-J2 cells, but had no significant effect on adhesion (Fig. 5A). At $0.8 \mathrm{mM}$ adhesion was also reduced twofold compared to the control while invasion was further lowered to $14 \%$. In order to check that this was
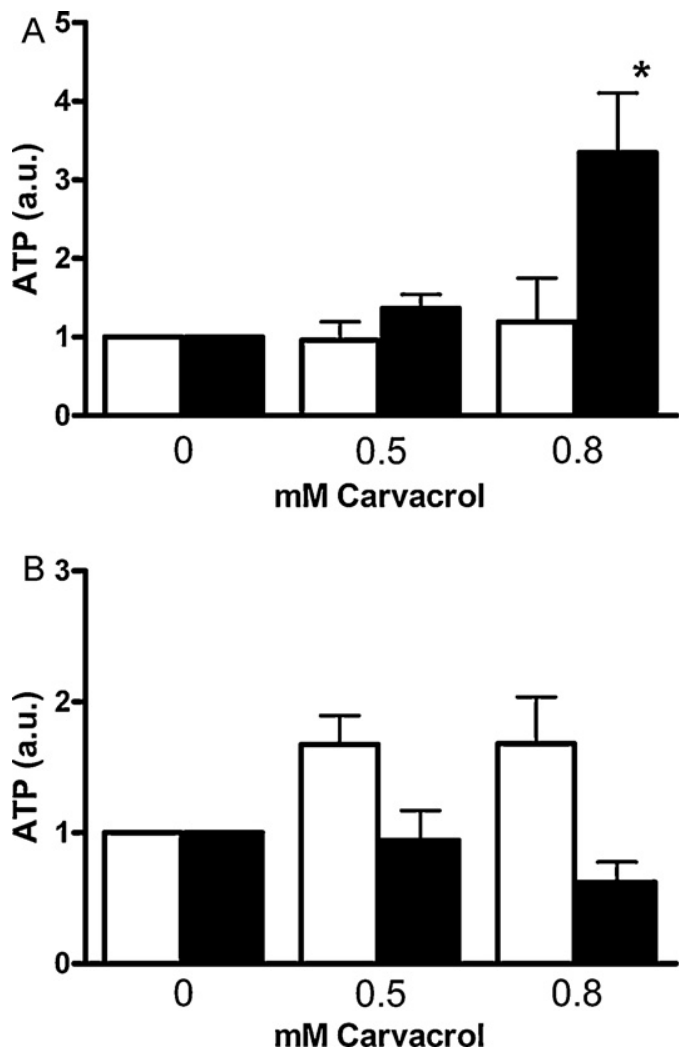

Fig. 4. Intracellular (white bars) and extracellular (black bars) ATP levels of Salmonella Typhimurium grown in the presence of $0,0.5$ and $0.8 \mathrm{mM}$ carvacrol. Shown is the mean and SEM of three independent experiments of quadruplicate samples. (A) S. Typhimurium DT104 grown to log phase ( $3 \mathrm{~h}$ ) in the presence of carvacrol, (B) S. Typhimurium DT104 grown o/n in the presence of carvacrol. * indicates statistical significance.
Table 1

Cytotoxic effects of carvacrol on epithelial IPEC-J2 cells.

\begin{tabular}{lc}
\hline Carvacrol $(\mathrm{mM})$ & \% Dead cells $($ mean $\pm \mathrm{SEM})$ \\
\hline 0 & $2.1 \pm 0.5$ \\
0.3 & $5.2 \pm 1.1$ \\
0.7 & $16.7 \pm 4.0$ \\
1.0 & $48.5 \pm 15.9$
\end{tabular}

Depicted are the mean and SEM of 5 independent experiments.

not a cell-specific phenomenon, similar experiments were performed with human Caco- 2 cells. In these experiments a similar trend was observed (Fig. 5B) with a reduced invasion of cells upon carvacrol treatment of $S$. Typhimurium but no difference in adhesion.

\section{7. $p B D-2$ gene expression}

Upon infection with Salmonella Typhimurium, IPEC-J2 cells increase the gene expression of host defense peptides such as pBD-2 (Veldhuizen et al., 2009). After $6 \mathrm{~h}$ of infection, $\mathrm{pBD}-2$ gene expression levels of $S$. Typhimurium DT104 infected IPEC-J2 cells (0 mM carvacrol) were approximately 9 times higher than the non Salmonellainfected control cells, while after $24 \mathrm{~h}$ pBD-2 levels were $>250$ times higher (Fig. 6A and B). When $S$. Typhimurium DT104 was grown in the presence of $0.5 \mathrm{mM}$ or $0.8 \mathrm{mM}$ carvacrol before infection of IPEC-J2 cells, this pBD-2 upregulation was partially inhibited. At both time points a
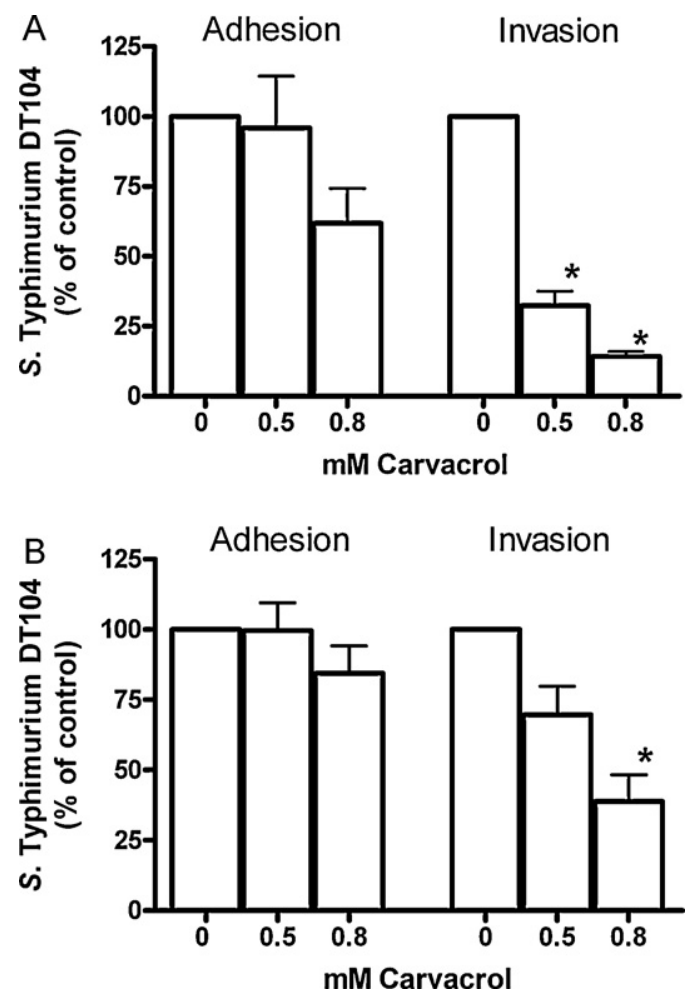

Fig. 5. Adhesion and invasion of IPEC-J2 (A) and Caco-2 (B) cells by $S$. Typhimurium DT104. Adhesion and invasion are shown as percentages relative to the control ( $0 \mathrm{mM}$ carvacrol, set at $100 \%)$. Shown are the mean and SEM of five independent experiments. * indicates statistical significance. 
twofold decrease in pBD-2 gene expression compared to the $0 \mathrm{mM}$ carvacrol sample was observed, although only the $24 \mathrm{~h}$ levels reached statistical significance.

\subsection{Detection of cytokines}

Infection of IPEC-J2 cells with S. Typhimurium DT104 resulted in a clear upregulation after 4, 6 and $24 \mathrm{~h}$ of IL-8 (Fig. 7A). Control samples of non-infected cells showed increased IL-8 levels as well, indicating that IPEC-J2 cells have a constitutive expression of this chemokine under our culture conditions. S. Typhimurium DT104 grown to log phase in the presence of carvacrol caused a slightly lower level of IL-8 but this did not reach statistical significance. Similarly, the TNF $\alpha$, IL- 6 or IL-1B expression was measured upon Salmonella infection with and without carvacrol treatment (Fig. 7B-D). Infection only had a minor effect on the expression of these cytokines with observed increases in the $\mathrm{pg} / \mathrm{ml}$ range compared to $\mathrm{ng} / \mathrm{ml}$ for IL-8. In addition no significant effect of carvacrol could be determined.

\section{Discussion}

The European ban on prophylactic use of antibiotics in order to reduce antimicrobial resistance development has
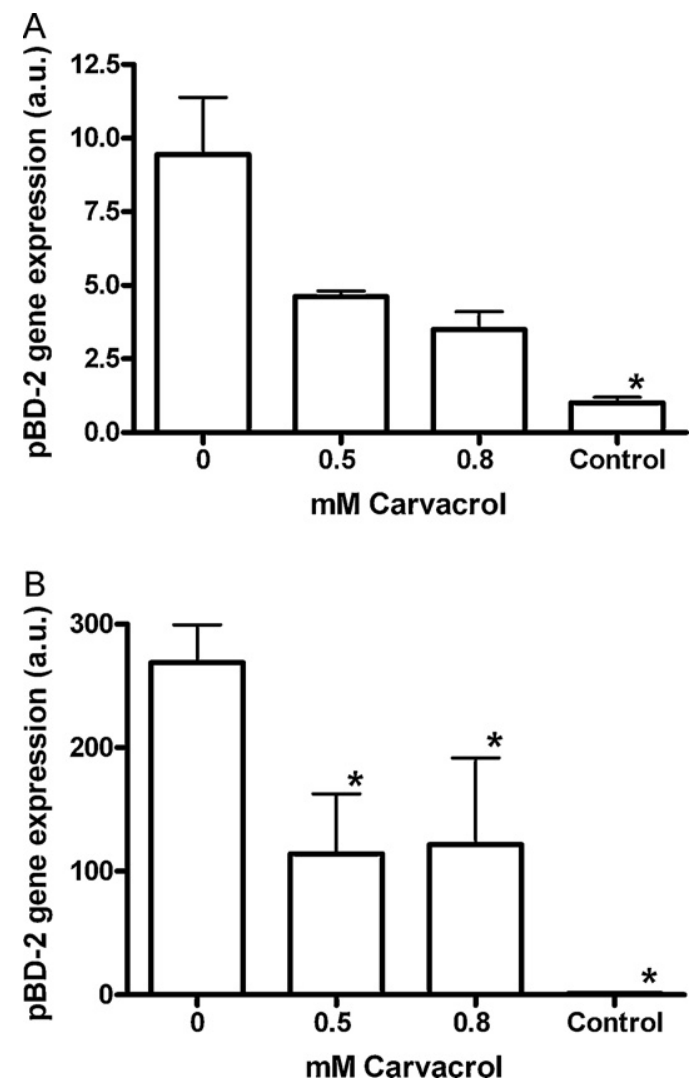

Fig. 6. Gene expression of pBD-2 in IPEC-J2 cells upon $S$. Typhimurium DT104 infection. Shown is the mean and SEM of three independent experiments in duplicate. (A) Gene expression $6 \mathrm{~h}$ post infection, (B) gene expression $24 \mathrm{~h}$ post infection. * indicates statistically significant difference compared to the $0 \mathrm{mM}$ carvacrol sample. raised the interest in the use of phytochemicals, such as carvacrol, as feed additives to increase the intestinal health of swine and prevent infections. In order to determine the exact mechanism of action of carvacrol or other antibacterial chemicals, studies are usually performed at concentrations close to, or higher than, the minimal inhibitory concentration (MIC) of this compound. However sub-lethal concentrations of chemicals can already have important effects on bacteria. Ultee and Smid showed that at low concentrations of carvacrol toxin production was inhibited in Bacillus cereus, while viability of this bacterium was unchanged (Ultee and Smid, 2001). Similarly, low sublethal concentrations of small and medium chain fatty acids affected gene expression of several virulence genes in Salmonella (Boyen et al., 2008).

In this study we determined the effect of sub-lethal concentrations of carvacrol on the virulence of $S$. Typhimurium DT104. Growth of S. Typhimurium was reduced at $>1 \mathrm{mM}$ carvacrol while it was completely inhibited at $2 \mathrm{mM}$. These MIC values are similar to most other studies describing direct antimicrobial effects of carvacrol in vitro (Burt, 2004). Interestingly, motility of Salmonella was greatly reduced at lower concentrations than growth inhibition, between 0.4 and $1 \mathrm{mM}$ carvacrol (Fig. 2), as has been described for $E$. coli (Burt et al., 2007). In these latter studies, the lack of motility of $E$. coli after incubation with $1 \mathrm{mM}$ carvacrol was attributed to the absence of the flagellum. For $S$. Typhimurium the effect of carvacrol seems to be different since no reduction in the number of flagella and the presence of flagellin was observed upon incubation with carvacrol (Fig. 3). This indicates that the loss of motility cannot be attributed to the loss of flagella but possibly to the loss of functionality of the flagellum.

Sub-lethal levels of carvacrol did not lead to decreased intracellular ATP levels in log phase or o/n cultures (Fig. 4). In log phase bacteria extracellular ATP levels were higher than non carvacrol-treated controls indicating that carvacrol caused some ATP leakage but that lost intracellular ATP was regenerated. Similar ATP leakage due to carvacrol has been described before but only at bactericidal concentrations of carvacrol (Ultee et al., 1999; Gill and Holley, 2006) and not at sub-lethal conditions. From the ATP results it is clear that loss of motility of $S$. Typhimurium is not related to intracellular ATP levels.

$S$. Typhimurium grown to log phase in the presence of 0.5 and $0.8 \mathrm{mM}$ carvacrol showed reduced invasion of intestinal cells, while adhesion was relatively unaffected (Fig. 5). The correlation between motility and invasion has been shown before, although other factors such as the type III secretion system encoded by genes on the Salmonella pathogenicity island I are equally important (Shah et al., 2011). In addition, we tested whether the host response to $S$. Typhimurium invasion was affected. The lowered invasion characteristic of carvacrol treated $S$. Typhimurium indeed led to a twofold lower pBD-2 gene expression (Fig. 6). In earlier studies, we hypothesized that, based on our experiments using heat or colistin-killed $S$. Typhimurium, invasion of live bacteria was required for the induction of pBD-2 gene expression (Veldhuizen et al., 2009). The results described in this report confirm that invasion and not adhesion is important for the level of 

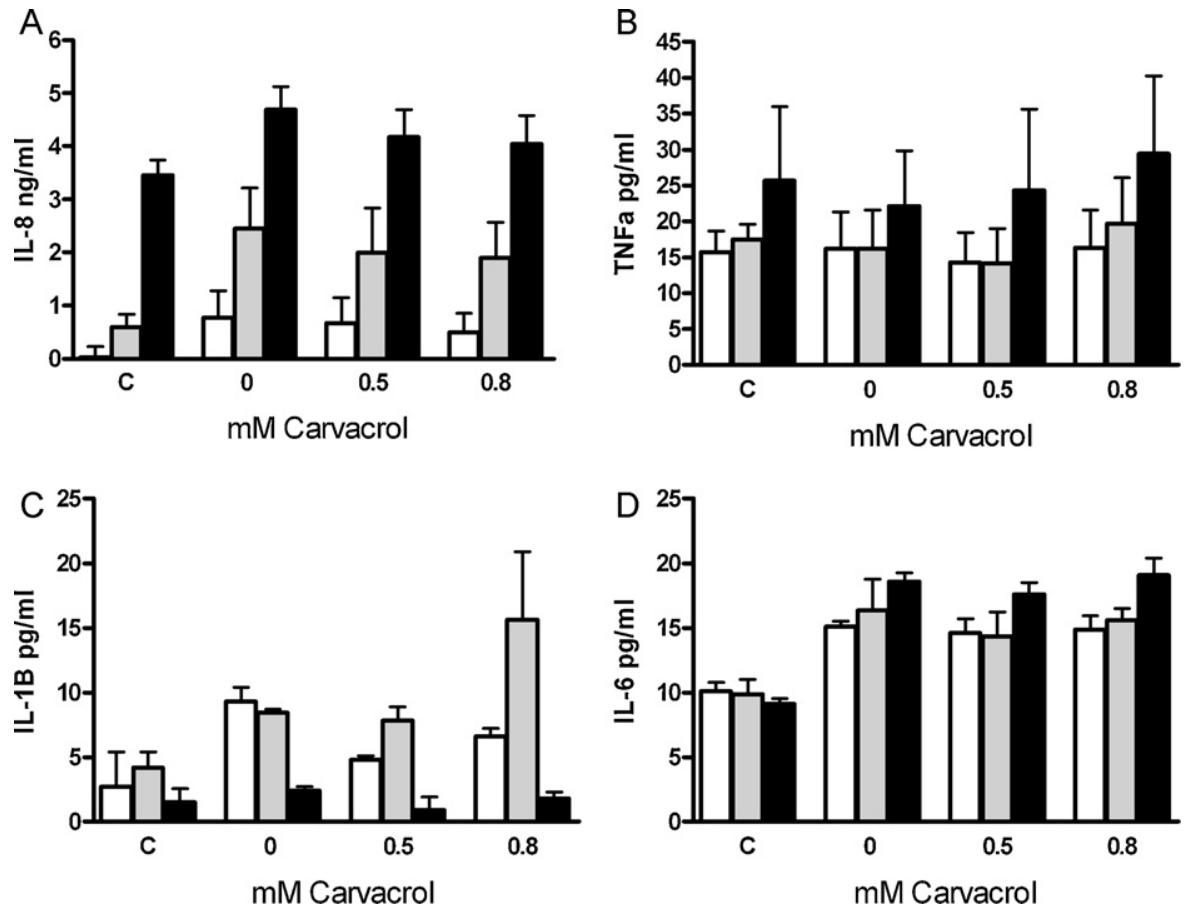

Fig. 7. Cytokine production of IPEC-J2 cells upon S. Typhimurium infection. IPEC-J2 were infected with carvacrol treated S. Typhimurium, IL-8 (A), TNF $\alpha$ (B) IL-1B (C) and IL6 (D) production was measured after 4 (white) 6 (grey) and $24 \mathrm{~h}$ (black bars). Shown is the mean and SEM of three independent experiments.

pBD-2 gene expression of the porcine epithelial cells. These results indicate that cytosolic immunosensors, such as NOD or NOD-like receptors (Delbridge and O'Riordan, 2007) could be involved in the host response towards $S$. Typhimurium. Reduced invasion of Salmonella did not lead to a changed cytokine expression profile of IPEC-J2 cells (Fig. 7), indicating that other signal transduction pathways lead to cytokine production compared to $\mathrm{pBD}-2$ production.

A major concern for the potential of carvacrol, or in general any other feed additive, is the potential toxicity towards mammalian cells. Our experiments showed that a sub-lethal concentration of carvacrol has toxic effects on the porcine intestinal epithelial cell line IPEC-J2. A similar cytotoxic effect of carvacrol, or reduced proliferation of cells under the influence of carvacrol has been shown for several other cells lines (Fabian et al., 2006; Karkabounas et al., 2006; Lampronti et al., 2006). However, one report describes that up to $5 \mathrm{mM}$ carvacrol did not affect the transepithelial electric resistance of porcine small intestinal epithelial cells (IPEC-1 cells) in vitro, implying that the toxicity is likely cell-type dependent (Roselli et al., 2007). In addition, several in vivo studies have been performed using carvacrol containing feed additives and these have not shown signs of great cytotoxicity (Windisch et al., 2008). This indicates that the use of cell lines is not always a good model to predict toxic effects in vivo. Another explanation is that the effectively available amount of carvacrol to interact with host cells is lower than calculated due to dilution effects along the gastrointestinal tract, and/or carvacrol binding to feed components. In addition, some studies have shown that small lipophillic compounds such as carvacrol are absorbed by the upper part of the intestine, after which they are metabolized (Kohlert et al., 2002; Stoni et al., 2006).

A lower amount of freely available carvacrol could also explain why in vivo the beneficial effects of carvacrol and other phytochemicals are less pronounced. Although several studies show effects of (carvacrol containing) feed additives on food conversion and growth, (reviewed in Burt, 2004; Baser, 2008; Windisch et al., 2008), the effects often seem marginal compared to the expectations based on in vitro data. This implicates that much optimization in the experimental set-up is required. This needs to include dose and composition of the phytochemicals given, but also timing of administration (for example pre or post weaning) could turn out to be crucial. Moreover, it would be beneficial to protect the active components until they can be released at the part of the intestine where they are required. Finally, determination of clear, reliable and reproducible read-out parameters is needed in order to fully compare and understand the described activities of phytochemical activity.

In conclusion, we have shown that a sub-inhibitory concentration of carvacrol affects virulence of Salmonella leading to reduced motility and invasion of epithelial cells. This is an important finding since sub-inhibitory concentrations are likely to occur in vivo when carvacrol is used as a feed additive. However, it is of the highest importance to better map the interplay of carvacrol with other feed and/ or intestinal components to understand its effect in vivo in the pig intestine. 


\section{Acknowledgments}

The authors would like to thank Chris Schneijdenberg for the negative staining experiments and the Veterinary Microbiological Diagnostic Center for their kind gift of the Salmonella clinical isolates used in this study. Anti-flagellin antibodies were a kind gift from Dr. Blocker and Dr. Minamino.

\section{References}

Baser, K.H., 2008. Biological and pharmacological activities of carvacrol and carvacrol bearing essential oils. Curr. Pharm. Des. 14, 31063119.

Boyen, F., Haesebrouck, F., Vanparys, A., Volf, J., Mahu, M., Van Immerseel, F., Rychlik, I., Dewulf, J., Ducatelle, R., Pasmans, F., 2008. Coated fatty acids alter virulence properties of Salmonella Typhimurium and decrease intestinal colonization of pigs. Vet. Microbiol. 132, 319-327.

Burt, S., 2004. Essential oils: their antibacterial properties and potential applications in foods - a review. Int. J. Food Microbiol. 94, 223-253.

Burt, S.A., van der Zee, R., Koets, A.P., de Graaff, A.M., van Knapen, F., Gaastra, W., Haagsman, H.P., Veldhuizen, E.J.A., 2007. Carvacrol induces heat shock protein 60 and inhibits synthesis of flagellin in Escherichia coli 0157:H7. Appl. Environ. Microbiol. 73, 4484-4490.

Chami, N., Bennis, S., Chami, F., Aboussekhra, A., Remmal, A., 2005. Study of anticandidal activity of carvacrol and eugenol in vitro and in vivo. Oral Microbiol. Immunol. 20, 106-111.

Delbridge, L.M., O’Riordan, M.X., 2007. Innate recognition of intracellular bacteria. Curr. Opin. Immunol. 19, 10-16.

Fabian, D., Sabol, M., Domaracká, K., Bujnáková, D., 2006. Essential oils their antimicrobial activity against Escherichia coli and effect on intestinal cell viability. Toxicol. In Vitro 20, 1435-1445.

Gill, A.O., Holley, R.A., 2006. Disruption of Escherichia coli, Listeria Monocytogenes and Lactobacillus Sakei cellular membranes by plant oil aromatics. Int. J. Food Microbiol. 108, 1-9.

Hendriksen, S.W., Orsel, K., Wagenaar, J.A., Miko, A., van Duijkeren, E., 2004. Animal-to-human transmission of Salmonella Typhimurium DT104A variant. Emerg. Infect. Dis. 10, 2225-2227.

Karkabounas, S., Kostoula, O.K., Daskalou, T., Veltsistas, P., Karamouzis, M., Zelovitis, I., Metsios, A., Lekkas, P., Evangelou, A.M., Kotsis, N., Skoufos, I., 2006. Anticarcinogenic and antiplatelet effects of carvacrol. Exp. Oncol. 28, 121-125.

Kohlert, C., Schindler, G., Marz, R.W., Abel, G., Brinkhaus, B., Derendorf, H., Grafe, E.U., Veit, M., 2002. Systemic availability and pharmacokinetics of thymol in humans. J. Clin. Pharmacol. 42, 731-737.

Lampronti, I., Saab, A.M., Gambari, R., 2006. Antiproliferative activity of essential oils derived from plants belonging to the magnoliophyta division. Int. J. Oncol. 29, 989-995.
Panella, N.A., Dolan, M.C., Karchesy, J.J., Xiong, Y., Peralta-Cruz, J., Khasawneh, M., Montenieri, J.A., Maupin, G.O., 2005. Use of novel compounds for pest control: insecticidal and acaricidal activity of essential oil components from heartwood of alaska yellow cedar. J. Med. Entomol. 42, 352-358.

Roselli, M., Britti, M.S., Le Huërou-Luron, I., Marfaing, H., Zhu, W.Y., Mengheri, E., 2007. Effect of different plant extracts and natural substances (PENS) against membrane damage induced by enterotoxigenic Escherichia coli K88 in pig intestinal cells. Toxicol. In Vitro 21, 224-229.

Schierack, P., Nordhoff, M., Pollmann, M., Weyrauch, K.D., Amasheh, S., Lodemann, U., Jores, J., Tachu, B., Kleta, S., Blikslager, A., Tedin, K., Wieler, L.H., 2006. Characterization of a porcine intestinal epithelial cell line for in vitro studies of microbial pathogenesis in swine. Histochem. Cell Biol. 125, 293-305.

Shah, D.H., Zhou, X., Addwebi, T., Davis, M.A., Orfe, L., Call, D.R., Guard, J., Besser, T.E., 2011. Cell invasion of poultry-associated Salmonella enterica serovar Enteritidis isolates is associated with pathogenicity, motility and proteins secreted by the type III secretion system. Microbiology 157, 1428-1445.

Si, W., Gong, J., Chanas, C., Cui, S., Yu, H., Caballero, C., Friendship, R.M., 2006. In vitro assessment of antimicrobial activity of carvacrol, thymol and cinnamaldehyde towards Salmonella serotype Typhimurium DT104: effects of pig diets and emulsification in hydrocolloids. J. Appl. Microbiol. 101, 1282-1291.

Stoni, A., Zitterl-Egelseer, K., Kroismayr, A., Wetscherek, W., Windisch, W., 2006. Tissue recovery of essential oils used as feed additive in piglet feeding and impact on nutrient digestibility. Proc. Soc. Nutr. Physiol. 15,60 .

Tampieri, M.P., Galuppi, R., Macchioni, F., Carelle, M.S., Falcioni, L., Cioni, P.L., Morelli, I., 2005. The inhibition of Candida Albicans by selected essential oils and their major components. Mycopathologia 159, 339345.

Ultee, A., Kets, E.P., Smid, E.J., 1999. Mechanisms of action of carvacrol on the food-borne pathogen Bacillus Cereus. Appl. Environ. Microbiol. 65, 4606-4610.

Ultee, A., Smid, E.J., 2001. Influence of carvacrol on growth and toxin production by Bacillus Cereus. Int. J. Food Microbiol. 64, 373-378.

Van Asten, Hendriks, H.G., Koninkx, J.F., Van der Zeijst, B.A., Gaastra, W., 2000. Inactivation of the flagellin gene of Salmonella Enterica serotype Enteritidis strongly reduces invasion into differentiated Caco- 2 cells. FEMS Microbiol. Lett. 185, 175-179.

Veldhuizen, E.J., Creutzberg, T.O., Burt, S.A., Haagsman, H.P., 2007. Low temperature and binding to food components inhibit the antibacterial activity of carvacrol against Listeria Monocytogenes in steak tartare. J. Food Prot. 70, 2127-2132.

Veldhuizen, E.J., Koomen, I., Ultee, T., van Dijk, A., Haagsman, H.P., 2009. Salmonella serovar specific upregulation of porcine defensins 1 and 2 in a jejunal epithelial cell line. Vet. Microbiol. 136, 69-75.

Windisch, W., Schedle, K., Plitzner, C., Kroismayr, A., 2008. Use of phytogenic products as feed additives for swine and poultry. J. Anim. Sci. 86, E140-E148. 